\title{
The effects of physical work, mental work, and quantity on children's time perception
}

\author{
MARSHALL ARLIN \\ University of British Columbia, Vancouver, British Columbia, Canada
}

\begin{abstract}
An experiment was conducted to examine the effects of work and quantity cues on children's time perception. Ninety-seven children in kindergarten and Grades 2, 4, and 6 lifted and transferred pipes under eight different conditions, after which they reproduced the perceived time taken to move the pipes. The conditions varied by quantity (two/four pipes), by mental work (nomatching/matching), and by physical work (light/heavy pipes). Significant main effects were found for quantity, physical work, and mental work, and for the quantity $\times$ age and mental work $\times$ physical work interactions. These results can help to disentangle possible confounds among these variables in the classic Piagetian experiments about their effects on time judgment and perception.
\end{abstract}

Piaget (1946, 1946/1971, 1973) argued that increased work expended on a task induces a temporal illusion, that is, the perception of increased duration. He found this effect of work or effort particularly among young children, but also among adults. Adults were influenced by effort, but they could use reflection to counteract its influence. Piaget also found that quantity (e.g., the number of pieces of wood moved) induced an illusion of increased duration. However, work took precedence over quantity, so that when making comparative duration judgments, children would focus on the cues of work or effort more than on those of quantity.

In Piaget's experiment (1946/1971), children used small pincers to transfer rectangular lead disks (greater effort) or triangular wooden disks (less effort) into a wooden box. According to Piaget, the transfer of the lead would seemingly involve more work because it was heavier and because the rectangular shapes were more difficult to pick up than the triangular wooden shapes. The majority of children did in fact think that the lead transfer took longer than the wood transfer. Piaget concluded that "children judge time by the work done which, in turn, is judged by its difficulty and the effort it demands rather than in quantitative terms (the number of pieces moved)" ( $\mathrm{Pi}$ aget, 1946/1971, p. 266, emphasis added).

Zuili and Fraisse (1966) were able to clarify Piaget's findings about work and quantity cues. In their study, children of ages 5,9 , and 13 years moved rings by hand or chips with a pair of tweezers. They found that children focused primarily upon quantity, and that children typically used only one criterion in their estimates. Fraisse (1961, 1963/1975; Fraisse \& Zuili, 1966; Zuili \& Fraisse,

I thank Yi-Ling Chow, Maria Oud, Fraser Hannah, and particularly Elizabeth Wellburn for their work as research assistants for this project. I appreciate the assistance provided by the Social Sciences and Humanities Research Council of Canada, which made this study possible. Address correspondence to Marshall Arlin, Department of Educational Psychology and Special Education, 2125 Main Mall, University of British Columbia, Vancouver, British Columbia V6T 1Z5, Canada.
1966) further clarified investigations about work and quantity with his notion of the number of perceived changes and his dual definition of work. Fraisse maintained that "for Piaget the essential seems to be the relationship between the work accomplished and the feeling of activity; for us it is the number of changes perceived" (Fraisse, 1963/1975, p. 233, footnote 10). This notion of perceived changes is one interpretation of the notion of quantity.

One of the difficulties with Piaget's and Fraisse's studies is that they were not designed to fully disentangle the differential effects of quantity and work. Certain features of their experimental designs make assessment of differential effects difficult. In Piaget's study, there is a confound between effort and quantity. Although effort differences remained constant (lead vs. wood), quantity did not. Harder work was most likely confounded with lesser quantity, and vice versa. Piaget did not provide group data about quantity differences.

A second confound is that between physical work and mental work. It is highly likely that the work condition required both physical work (picking up the heavier lead) and mental work (the attention required to use the pincers for picking up the rectangular lead disks). Piaget felt that both aspects represented "work," and he did not try to disentangle them: "the transfer of the lead, which is both heavier and also more difficult to pick up on account of its shape, seemingly involves 'more work"' (Piaget, $1946 / 1971$, p. 264). A similar confounding exists in Zuili and Fraisse's (1966) study. The task of placing the rings into the box likely required minimal cognitive effort, whereas transferring the chips with the tweezers likely required considerably greater attentional demands and greater mental effort. In Piaget's study, greater mental effort was confounded with lesser quantity, because the task was slower, and it also was confounded with greater physical effort, because the lead pieces were heavier. In Zuili and Fraisse's study, greater attention was confounded with lesser quantity because moving the chips 
with the tweezers required greater attention but was also slower, and consequently involved fewer chips. In both studies, quantity was not experimentally controlled. Children would work for a certain length of time and were allowed to move as many or as few pieces (quantity) as possible in that time. In the present experiment, quantity was experimentally controlled, in an attempt to help distinguish the effects of quantity from those of mental and physical effort.

Studies on the attentional hypothesis suggest that mental work should affect time perception (as reproduction) in a manner opposite to that of Piaget's predictions for the effect of physical work on time judgment. (Although Piaget (1946/1971) used both the judgment and reproduction paradigms, it would appear that most of his conclusions were based on children's judgments about time.) A number of authors have found that perceived time does decrease under conditions requiring active attention (Arlin, 1986a, 1986b; Burnside, 1971; Curton \& Lordahl, 1974; Fraisse, 1981, 1982, 1984; Frankenhaeuser, 1959; Friedman, 1982; Hicks, Miller, \& Kinsbourne, 1976; McKay, 1977; Zakay, Nitzan, \& Glicksohn, 1983). The attentional hypothesis suggests that tasks such as moving lead pieces with pincers (Piaget, 1946) or chips with tweezers (Zuili \& Fraisse, 1966) would distract attention from a hypothesized cognitive timer and consequently be perceived as shorter, rather than longer. The cognitive timer hypothesized by Frankenhaeuser (1959) and subsequent researchers (e.g., Hicks, Miller, \& Kinsbourne, 1976) is a biological/psychological construct whose primary function is to monitor the passage of time.

The purpose of the present experiment was to examine the effects of work and quantity cues on immediate time reproduction. It was hoped that the design would help to distinguish the effect of quantity (number of pieces moved) from effects of physical effort (weight) and mental effort (attention).

\section{METHOD}

\section{Subjects}

Participants in the initial sample were 140 pupils (35 each in kindergarten and Grades 2, 4, and 6) sampled from 17 classrooms in two schools in Vancouver, British Columbia. One of the schools contained a large number (approximately $75 \%$ ) of first- and secondgeneration immigrant children, whose language in the preschool years had been non-English (primarily Chinese or East Indian). Participants who were not fluent in English were omitted. The second school contained pupils whose maternal language was predominantly English. Both schools were characterized by an academic emphasis. Because of difficulties in comprehending the practice trials for the experimental tasks, 10 kindergarten children were initially omitted, and because of further difficulties with the tasks themselves, another 10 kindergarten children were omitted. Because of difficulties in understanding or performing the task, or because of incomplete data, 10 pupils were omitted from Grade 2, 8 from Grade 4, and 5 from Grade 6 , leaving a final sample of 97 . Of these, 47 were girls and 50 were boys. Initial analyses of variance revealed no main or interactive effects for sex, so this parameter is not discussed further. The mean ages in years (with standard deviations in parentheses) for the four grade levels were $5.84(.53), 7.79(.42), 9.92$
(.58), and $11.89(.52)$, or slightly younger than $6,8,10$, and 12 years of age.

\section{Materials}

The materials were eight steel pipes $(38 \times 3.2 \mathrm{~cm})$ and eight styrofoam "pipes" $(38 \times 3.5 \mathrm{~cm})$. The steel pipes were painted white to match the foam, and all 16 pipes looked similar. The steel pipes were thick and heavy, weighing approximately $1 \mathrm{~kg}(1,022 \mathrm{~g})$ each. The styrofoam pipes felt virtually weightless, and at $11 \mathrm{~g}$ were only about $1 \%$ the weight of the steel. Four of the foam and four of the steel pipes had three round, $1.5-\mathrm{cm}$ stickers placed vertically on the surface near one end. The stickers were in a variety of bright colors, including red, yellow, blue, green, and so forth. There were three receptacles for the pipes, a starting receptacle, an overflow receptacle (both $30 \times 40 \mathrm{~cm})$, and a target receptacle $(30 \times 60 \mathrm{~cm})$. All were painted white. The starting and overflow receptacles had painted nails along the edges to keep pipes placed in them from rolling out. The target receptacle had $105-\mathrm{cm}$ channels, set off by bolts, into which a single pipe could be placed. At the bottom of each of these channels were two circles, each of a different color, placed vertically, one immediately above the other.

\section{Procedure}

In the first of two practice procedures, the children were directed to press a button on the computer which emitted a continuous tone. Then they were told they would hear similar tones made by the computer, after which they would press the button and repeat the tone for the same amount of time. Then they heard three tones with durations of 2,10 , and $5 \mathrm{sec}$, after each of which they pressed the computer button. The children were given practice if they had difficulty.

In the second practice procedure, the children faced the three receptacles: starting on the left, overflow in the middle, and target on the right. With spacing between receptacles, the distance from the middle of the starting receptacle to the middle of the target receptacle was approximately $1 \mathrm{~m}$. The children were asked to move two foam pipes and two steel pipes, one at a time, from the starting to the target receptacle. Experimenters permitted additional practice, if necessary, to ensure that all participants correctly discriminated the labels "foam pipe" and "steel pipe." The participants were then instructed to match the bottom circle on a foam and a steel pipe to the color of the bottom circle on the target channels, and to place each pipe in the appropriate channel. The second colored circle on each pipe served as a distractor, to increase the amount of attention required. The four practice pipes were slightly shorter than the pipes used in the experiment, and the order of practice was randomized.

The children were then told that they would move each pipe on the verbal signal "Go" from the experimenter. They were told to mentally measure the time between the first (onset) tone of the computer, accompanied by the verbal command "Go," and the second (offset) tone, accompanied by a verbal command "Stop." Even if pupils finished moving the pipes early, they were to wait for the second "beep" + "Stop" and reproduce the time between the two tones, as described below. One experimenter observed the computer screen, which cued the rate of the signal by flashing the signal on the screen without auditory accompaniment.

The children then practiced with pipes to make sure they understood the procedure. The children were told that they could put the pipes in the middle (overflow) receptacle if they did not have time to finish a move or to find a match, because they had to start moving a new pipe when they heard the next signal. Finally, the children were told that after they had moved a set of pipes and heard the "beep" +"Stop" signal, they would have to press a computer button for the same amount of time as they perceived it to have taken to move the whole set of pipes. This was the same button that produced an audible signal as that used in the first practice session. The children then practiced moving pipes to ensure that they 
understood the procedure, and that they understood that the duration to be reproduced was the whole interval between onset and offset tones.

There were eight possible transfer conditions, based on combinations of physical work (foam = easier, steel $=$ harder), mental work (no-matching = easier, matching = harder), and quantity (two pipes, four pipes). Each pupil was randomly assigned to one of eight different orders of conditions by a modified Latin squares assignment. Each pupil transferred the pipes according to each of the eight factorial conditions, and, after each condition, pressed the computer button for the perceived duration of the transfer.

The total transfer interval allowed in each of the eight conditions was $12 \mathrm{sec}, 6 \mathrm{sec}$ per pipe in the two-pipe conditions and $3 \mathrm{sec}$ per pipe in the four-pipe condition. The subjects were able to maintain the pace with accuracy in all conditions except when matching with four pipes, which caused some difficulty, particularly among younger pupils, and required use of the overflow receptacle. Times for each of the eight conditions were recorded to 100ths of a second by the computer. Two experimenters were used to expedite the process, one to give the verbal cues and the other to place the appropriate number and type of pipes in the starting receptacle prior to each transfer.

\section{Definitions}

For the purpose of this study, quantity is operationally defined as the number of individual pipes moved, one at a time. This is congruent with other researchers' definitions of quantity as number of discrete events or objects, such as number of items or frequency of occurrences. Physical work is operationally defined as the amount of physical effort required to lift pipes individually and carry them a distance of approximately $1 \mathrm{~m}$ and set them down. Differential physical work was assumed to be induced by differential weights of the pipes. Mental work was operationally defined as the amount of attention presumed required by a task in which matching of two colored circles was or was not required. Time perception is defined as the immediate reproduction of durations of $12 \mathrm{sec}$.

\section{RESULTS}

The mean reproduced durations of the eight conditions across the four grade levels, as well as the respective standard deviations, are given in Table 1. Weighted group means are used in the discussion below.
A $4 \times 2 \times 2 \times 2$ split-plot analysis of variance was conducted on the time reproduction scores. Grade level (K, $2,4,6)$ was the between-subject factor, and physical work, mental work, and quantity were the within-subject factors. Because a selection effect probably caused the final 15 kindergarten children included in the sample to be atypical of the general population, all the analyses were repeated with a subsample of Grades 2,4 , and 6 ; however, all effects significant or nonsignificant in one sample were also significant or nonsignificant in the other, so the results from the full sample are reported here.

There was a significant effect of quantity $[F(1,93)=$ $20.48, p<.001]$. Two-pipe intervals were reproduced as $4.66 \mathrm{sec}$, compared with $5.38 \mathrm{sec}$ for four-pipe intervals. Moreover, the quantity effect interacted significantly with age $[F(3,93)=8.10, p<.001]$. The younger the child was, the greater the effect, with more pipes resulting in greater time reproduction, except that the pattern was reversed in sixth graders. Kindergartners reproduced the four-pipe intervals as $1.25 \mathrm{sec}$ longer than the twopipe intervals, and second graders as $1.0 \mathrm{sec}$ longer. By fourth grade, the difference was only $.41 \mathrm{sec}$. By contrast, sixth graders reproduced the four-pipe interval as $.37 \mathrm{sec}$ shorter than the two-pipe interval.

The effect of mental work (matching colored circles) was also significant $[F(1,93)=5.92, p<.05]$. There was a significant interaction of mental work with physical work $[F(1,93)=6.82, p<.01]$. Mental work (matching) resulted in shorter reproduced times under heavier (four-pipe) physical work (5.1 vs. $5.6 \mathrm{sec})$, but the times were almost identical under light (two-pipe) physical work ( 4.9 vs. $5.0 \mathrm{sec}$ ). Another way of considering this interaction is that the lengthening effect of physical work was found only under conditions of low mental work (no-matching). Under the higher mental work of matching, moving the steel was perceived to take as long as moving the foam.

There was a significant effect of physical work $[F(1,93)$ $=16.50, p<.001]$. Moving steel pipes was perceived

Table 1

Reproduction Times (in Seconds)

\begin{tabular}{|c|c|c|c|c|c|c|c|c|}
\hline & \multicolumn{2}{|c|}{ No-Match } & \multicolumn{2}{|c|}{ Match } & \multicolumn{2}{|c|}{ No-Match } & \multicolumn{2}{|c|}{ Match } \\
\hline & 2 Foam & 2 Steel & 2 Foam & 2 Steel & 4 Foam & 4 Steel & 4 Foam & 4 Steel \\
\hline \multicolumn{9}{|c|}{ Kindergarten } \\
\hline $\begin{array}{l}M \\
S D\end{array}$ & $\begin{array}{l}2.69 \\
1.33\end{array}$ & $\begin{array}{l}3.69 \\
1.78\end{array}$ & $\begin{array}{l}3.00 \\
1.62\end{array}$ & $\begin{array}{l}3.57 \\
1.59\end{array}$ & $\begin{array}{l}4.36 \\
2.12\end{array}$ & $\begin{array}{l}4.65 \\
2.19\end{array}$ & $\begin{array}{l}4.32 \\
2.32\end{array}$ & $\begin{array}{l}4.61 \\
2.49\end{array}$ \\
\hline \multicolumn{9}{|c|}{ Grade 2} \\
\hline $\begin{array}{l}M \\
S D\end{array}$ & $\begin{array}{l}2.86 \\
0.85\end{array}$ & $\begin{array}{l}3.46 \\
1.05\end{array}$ & $\begin{array}{l}3.28 \\
1.38\end{array}$ & $\begin{array}{l}3.87 \\
1.13\end{array}$ & $\begin{array}{l}4.70 \\
1.70\end{array}$ & $\begin{array}{l}4.83 \\
1.21\end{array}$ & $\begin{array}{l}3.92 \\
1.05\end{array}$ & $\begin{array}{l}4.01 \\
1.13\end{array}$ \\
\hline \multicolumn{9}{|c|}{ Grade 4} \\
\hline $\begin{array}{l}M \\
S D\end{array}$ & $\begin{array}{l}4.90 \\
2.24\end{array}$ & $\begin{array}{l}5.71 \\
2.85\end{array}$ & $\begin{array}{l}4.89 \\
2.95\end{array}$ & $\begin{array}{l}4.89 \\
2.83\end{array}$ & $\begin{array}{l}5.53 \\
2.95\end{array}$ & $\begin{array}{l}5.86 \\
2.75\end{array}$ & $\begin{array}{l}5.33 \\
2.82\end{array}$ & $\begin{array}{l}5.32 \\
1.99\end{array}$ \\
\hline \multicolumn{9}{|c|}{ Grade 6} \\
\hline $\begin{array}{l}M \\
S D\end{array}$ & $\begin{array}{l}6.95 \\
2.61 \\
\end{array}$ & $\begin{array}{l}7.31 \\
2.56 \\
\end{array}$ & $\begin{array}{l}6.95 \\
2.65 \\
\end{array}$ & $\begin{array}{l}6.51 \\
2.59 \\
\end{array}$ & $\begin{array}{l}6.45 \\
2.15 \\
\end{array}$ & $\begin{array}{l}7.21 \\
1.98 \\
\end{array}$ & $\begin{array}{l}6.27 \\
2.12 \\
\end{array}$ & $\begin{array}{l}6.30 \\
2.22 \\
\end{array}$ \\
\hline
\end{tabular}


as requiring more time than moving foam pipes ( $5.00 \mathrm{vs}$. $5.31 \mathrm{sec})$. The interaction of physical work with grade was not significant.

Finally, there was a significant effect for grade level $[F(3,93)=12.93, p<.001]$. All grades underestimated the stimulus interval, with the greatest underestimation at the younger grades. The time reproductions were 3.86, $3.87,5.30$, and $6.74 \mathrm{sec}$ for Grades $K, 2,4$, and 6 , respectively.

\section{DISCUSSION}

\section{Limitations}

The conclusions are subject to the following limitations to generalization. First, because of experimental attrition, it is likely that the kindergarten sample represented brighter children of this age range. Second, conclusions are limited to the small sampling from the domains of quantity and work, as is also true of the experiments of Piaget (1946/1971, pp. 264-268) and Zuili and Fraisse (1966). Third, conclusions must be limited to the 12-sec durations used. Fourth, it could be argued that the brevity of the children's responses may indicate that some children did not understand, or misinterpreted, the task. Children on average reproduced a 5-sec interval to a 12-sec stimulus duration. It might be argued that children thought they were to reproduce the length of each interval, rather than the total 12-sec interval between the start signal and the stop signal. I believe, however, from observing the children's performance, both during the task and during the two practice procedures, that children included in the final sample did understand the task. Fifth, as is typical of experiments spanning the age range of this study, the tasks undoubtedly represented different levels of physical and cognitive intensity to the younger children than they did to the older children, so total equality of treatments across ages is not claimed.

Finally, the design, which was structured to disentangle the confound of work and quantity, is susceptible to its own confound between quantity and rest time. In the two-pipe condition, the children had to move two pipes at 6 sec each. Since children could move each pipe in approximately $3 \mathrm{sec}$, the two-pipe condition comprised approximately $3 \mathrm{sec}$ moving, $3 \mathrm{sec}$ pausing, $3 \mathrm{sec}$ moving, and $3 \mathrm{sec}$ pausing. There is a large body of research suggesting that an empty interval (the pause) is perceived as longer than an interval filled with activity (see, e.g., Fraisse, 1963/1975 for a review). Since the results indicated a significantly reduced time reproduction for the two-pipe condition, and the pauses should have increased the time reproduction, it is assumed that the quantity effect was robust, and evident in spite of the potentially opposite effect of the pauses.

\section{Conclusions}

In this experiment, greater quantity and physical work and less mental work were associated by children with greater time. This finding is not fully explained by the "more is more" hypothesis (Levin, 1977, 1979; Levin
\& Gilat, 1983), because in Grades K, 2, and 4, the quantity cue was particularly salient. Quantity thus appears to be one of the cues particularly suited for reproduced time or experiential time. This supports the conclusions of Arlin (1986a, 1986b), Matsuda (1965, 1967), and Zuili and Fraisse (1966).

This finding helps clarify the early work of Piaget on this topic. Piaget (1946/1971) argued that work was more salient than quantity, especially for younger children, although he did say it was not clear what criteria they used to estimate the duration of their own actions, which must be distinguished from estimation of the duration of a physical event. Even the youngest children in the present study appeared to use quantity cues without difficulty. The significant grade $\times$ quantity interaction, indicating that the quantity cue decreased with age, is contrary to Piaget's implication that the effect of quantity would increase with age and replace work as a more salient cue.

The positive relationship between quantity and reproduced time is consistent with predictions from the storage size hypothesis (Ornstein, 1969). It generalizes the relation between quantity and remembered duration (Block, 1974; McClain, 1983; Mulligan \& Schiffman, 1979) among adults to young children. The finding is also congruent with adult studies in which filled intervals were perceived as longer than empty intervals (Buffardi, 1971; Mo, 1975; Thomas \& Brown, 1974), as well as with the younger samples of Arlin (1986a, 1986b).

Of particular interest was the interaction between quantity and age. This interaction was in fact disordinal, with the positive effect decreasing with age, and reversing at the highest age ( 12 years). I speculate that one reason for this pattern is that the older children ( 12 years) were becoming aware of potential inverse relations between quantity-speed and time (Piaget, 1946/1970) and adjusted their time reproductions accordingly. They may have overcompensated, which resulted in shorter estimates of durations filled with greater quantity. Future research could benefit from direct assessment of children's developing notions of time and quantity, and of the degree to which cognitive developmental differences influence time perception and reproduction under varying conditions of quantity and work.

The results for the significant effects of both mental work and physical work must be considered in light of the significant interaction between these two factors. It would appear that mental effort, perhaps by distracting attention from a cognitive timer, causes children to deemphasize the cue of physical work. Conversely, heavier physical effort may cause children to de-emphasize the cue of mental effort. Although conclusions based on interactions must be considered speculative, this finding would provide one explanation of the finding that children tend to use a single cue in their temporal judgments (Fraisse, 1963/1975; Zuili \& Fraisse, 1966). However, the results do not permit the conclusion that children rely exclusively on only one cue. It is reasonable to interpret the results as suggesting that some, albeit small, degree of additivity and interaction of cues might be present (cf. 
Levin \& Gilat, 1983), although a single cue may be more salient than other de-emphasized cues.

Indirect evidence of the effect of mental work (attention) is also plausible. All children significantly underestimated the stimulus interval of $12 \mathrm{sec}$ by a factor of about $2 \frac{1}{2}$ (5-sec average reproduction time). At first glance, it might appear that such a significant underestimation indicates that some of the children did not understand the time reproduction task. However, children were reproducing an interval filled with activity to which they had to attend with an empty interval. It is likely that when they reproduced the computer tone, without other engaging activities, their attention refocused on the cognitive timer, and the subjective perception of a duration increased. It is plausible that 4 or $5 \mathrm{sec}$ with little to do except think about time seemed to take as long as $12 \mathrm{sec}$ actively engaged. This idea is further supported by the fact that in the practice procedure when an empty interval (with a computer tone) was reproduced by an equally empty interval (including the tone), the times were much more similar. The 10-sec stimulus interval was reproduced as $9.8,9.3,7.0$, and $8.9 \mathrm{sec}$ by children in Grades $\mathrm{K}$, 2,4 , and 6 , respectively. I suggest that this indirect evidence supports the predictions of the attentional hypothesis (Hicks et al., 1976) and extends support of this hypothesis from adults (Burnside, 1971; Curton \& Lordahl, 1974; McKay, 1977; Zakay et al., 1983) to children, as did Arlin (1986a, 1986b).

Attentional and quantity factors may affect time reproduction in opposite directions. Where the effects of the two factors are equivalent, they may cancel one another out, resulting in no net effect. In other words, quantity could increase perceived time, but attention to changes inherent in certain types of quantity (as in the present study) would decrease perceived time. Quantity could reduce perceived time to the extent that quantity of changes distracts attention from the cognitive timer, in accord with the attentional hypothesis, and it could increase perceived time in accord with the storage size hypothesis. Any resultant increase or decrease in perceived time could be the net result of these competing effects.

To summarize, the effects of quantity, mental work, and physical work were separated and were found to affect children's time perception. This study represents an attempt to disentangle these factors, which may have been confounded in previous research such as the classic studies by Piaget, Fraisse, and their colleagues. Results may suggest limitations to Piaget's hypothesis about the relative saliency of work cues over quantity cues. Research investigating both the attentional and storage size hypotheses may be useful for further clarifying Piaget's and Fraisse's results, and for studying children's time perception more generally.

\section{REFERENCES}

ArLIN, M. (1986a). The effects of quantity and depth of processing on children's time perception. Journal of Experimental Child Psychology, 42, 84-98.
ARLIN, M. (1986b). The effects of quantity, complexity, and attentional demand on children's time perception. Perception \& Psychophysics, 40, 177-182.

Block, R. A. (1974). Memory and the experience of duration in retrospect. Memory \& Cognition, 2, 153-160.

BuFfard, L. (1971). Factors affecting the filled-duration illusion in the auditory, tactual, and visual modalities. Perception \& Psychophysics, 10, 292-294.

BURNSIDE, W. (1971). Judgment of short time intervals while performing mathematical tasks. Perception \& Psychophysics, 9, 404-406.

Curton, E. D., \& LordahL, D. S. (1974). Effects of attentional focus and arousal on time estimation. Journal of Experimental Psychology, $103,861-867$.

Fraisse, P. (1961). Influence de la duree et de la frequence des changements sur l'estimation du temps [The effect of duration and frequency of changes on time estimation]. Année Psychologique, 61, 325-339.

Fraisse, P. (1975). The psychology of time. New York: Harper \& Row. (Original work published 1963)

FraIsse, P. (1981). Cognition of time in human activity. In G. D'Ydewalle \& W. Lens (Eds.), Cognition in human motivation and learning (pp. 233-259). New York: Erlbaum.

Fraisse, P. (1982). The adaptation of the child to time. In The developmental psychology of time (pp. 113-140). New York: Academic Press.

Fraisse, P. (1984). Perception and estimation of time. Annual Review of Psychology, 35, 1-36.

Fraisse, P., ZuiLI, N. (1966). L'estimation de la duree [The estimation of duration]. In Psychologie et epistemologie genetique: Themes Piagetiens (pp. 253-269). Paris: Dunod.

FrankenhaEuSER, M. (1959). Estimation of time: An experimental study. Stockholm: Almqvist \& Wisksell.

FRIEDMAN, W. J. (Ed.). (1982). The developmental psychology of time. New York: Academic Press.

Hicks, R. E., Miller, G. W., \&insbourne, M. (1976). Prospective and retrospective judgments of time as a function of information processed. American Journal of Psychology, 90, 431-446.

LEVIN, I. (1977). The development of time concepts in young children: Reasoning about duration. Child Development, 48, 435-444.

LEVIN, I. (1979). Interference of time-related and unrelated cues with duration comparisons of young children: Analysis of Piaget's formulation of the relation of time and speed. Child Development, 50 , 469-477.

LEVIN, I., \& GILAT, I. (1983). A developmental analysis of early time concepts: The equivalence and additivity of the effect of interfering cues on duration comparisons of young children. Child Development, 54, 78-83.

Matsuda, F. (1965). Development of time estimation: II. Effects of frequency of sounds given during standard time. Japanese Journal of Psychology, 36, 285-294.

MATSUDA, F. (1967). Development of time estimation: III. Effects of frequency of sounds given during standard time and reproduced time. Japanese Journal of Psychology, 37, 285-294.

MCCLAIN, L. (1983). Interval estimation: Effect of processing demands on prospective and retrospective reports. Perception \& Psychophysics, 34, $185-189$.

McKay, T. D. (1977). Time estimation: Effects of attentional focus and of a comparison of interval conditions. Perceptual \& Motor Skills, 45, 584-586.

Mo, S. S. (1975). Temporal reproduction of an interval as a function of numerosity. Bulletin of the Psychonomic Society, 5, 165-167.

Mulligan, R. M., \& Schiffman, H. R. (1979). Temporal experience as a function of organization in memory. Bulletin of the Psychonomic Society, 14, 417-420.

ORNSTEIN, R. E. (1969). On the experience of time. London: Routledge \& Kegan Paul.

Piaget, J. (1946). Le développement de la notion de temps chez l'enfant [The child's conception of time] (1st ed.). Paris: Presses Universitaires de France.

Piaget, J. (1970). The child's conception of movement and speed (G. E. T. Holloway \& M. J. Mackenzie, Trans.). New York: Ballantine. (Original work published 1946)

Piaget, J. (1971). The child's conception of time (A. J. Pomerans, Trans.). New York: Ballantine. (Original work published 1946) 
Piaget, J. (1973). Le développement de la notion de temps chez l'enfant [The child's conception of time] (2nd ed.). Paris: Presses Universitaires de France.

Thomas, E. A. C., Brown, I., JR. (1974). Time perception and the filled-duration illusion. Perception \& Psychophysics, 16, 449-458.

ZakaY, D., Nitzan, D., Guicksohn, J. (1983). The influence of task difficulty and external tempo on subjective time estimation. Perception \& Psychophysics, 34, 451-456.
Zuili, N., Fraisse, P. (1966). L'estimation du temps en fonction de la quantité de mouvements effectives dans une tache. Etude genetique. [Time estimation as a function of quantity of movements in a task. A developmental study.] Année Psychologique, 6, 383-396.

(Manuscript received October 26, 1987; revision accepted for publication August 23, 1988.)

\title{
Announcement
}

\author{
The International Society for Psychophysics \\ announces the \\ 5th ANNUAL FECHNER DAY MEETING \\ Cassis, France (near Marseille) \\ October 21-24, 1989
}

The meeting will be devoted to panel-led theme sessions, poster sessions, invited talks, and various social activities.

For further information, please write: Georges Canevet, CNRS-LMA, BP 71, 13402 Marseille, Cedex 9, France (Electronic mail: CAMILLE@FRMOP11.BITNET) or Robert Teghtsoonian, Clark Science Center, Smith College, Northampton, MA 01063, U.S.A. (Electronic mail: RTEX@SMITH.BITNET). 